\title{
Polymer Possessing Diaza-18-crown 6-Ether Linked by $\pi$-Conjugated Aminopenta-2,4-dienylidene Groups Generated by Ring-opening of Pyridinium Ring
}

\author{
Isao YAMAGUCHI, ${ }^{\dagger}$ Saki SHINGAI, and Moriyuki SATO \\ Department of Material Science, Faculty of Science and Engineering, Shimane University, \\ 1060 Nishikawatsu, Matsue 690-8504, Japan
}

(Received February 9, 2007; Accepted April 14, 2007; Published May 29, 2007)

\begin{abstract}
KEY WORDS Diaza-18-crown 6-Ether / Piperadine / Ring-opening / Pyridinium Ring / Inclusion /
\end{abstract} [doi:10.1295/polymj.PJ2006236]

Polymers possessing crown ether and diazacrown ether have attracted much attention due to their potential usability for separators of ionic species, chemosensors, and ion conductors. ${ }^{1-4}$ The structures of units linked to the crown ether and the diazacrown ether in the polymers are important for their applications since chemical properties of the polymers are affected by the structures of the linkers. For example, polymers containing the diazacrown ether linked by amide groups or imide groups show unique optical and electrochemical properties on the basis of functionalities of the linkers. ${ }^{5,6}$ To the best of our knowledge, there is no report on main chain polymers possessing the diazacrown ether linked by $\pi$-conjugated chains. Such a polymer will show interesting chemical properties upon complexation of the diazacrown ether with metal ions since the $\pi$-conjugated system may expand through the metal complex of the diazacrown ether. Investigation of the chemical properties of the polymer will give new fundamental information for construction of polymers having ion sensing and separating functionalities.

We previously reported synthesis of $\pi$-conjugated polymers by reaction of $N$-(2,4-dinitrophenyl)pyridinium chloride (1) with 2,5-dimethyl-1,4-phenylenediamine. $^{7}$ The polymers were consisted of 5-(2,5dimethyl-1,4-phenylene)penta-2,4-dienylideneammonium chloride unit and $N$-2,5-dimethyl-1,4-phenylene diaza[12]annulenium dichloride unit that were generated by ring-opening of the pyridinium ring of $\mathbf{1}$.

In addition, we have found that reaction of 1 with aliphatic diamines provides structurally controlled polymers consisted of 5-alkane-penta-2,4-dienylideneammonium chloride unit. These polymers have a positive charge on the iminium group $\left(-(\mathrm{R}) \mathrm{N}^{+}=\mathrm{C}-\right)$ that may induce unique optical and electrochemical properties.
In this work, we describe results of the reaction of 1 with 4,13-diaza-18-crown 6-ether (DA18C6), the structure, optical and electrochemical properties, and metal complexation of the polymer. A polymer obtained by the reaction of $\mathbf{1}$ with piperadine and model compounds are also reported.

The reactions of 1 with DA18C6 and piperadine caused ring-opening of the pyridyl ring of $\mathbf{1}$ to provide polymers polymer-1 and polymer-2 in 43 and 93\% yields, respectively (Scheme 1a). The lower yield of polymer-1 than polymer-2 seems to be ascribed to formation of low molecular weight products that were removed by repeated reprecipitations. Model compounds model-1 and model-2 were synthesized by the reactions of 1 with 1-aza-18-crown 6-ether and piperidine, respectively (Scheme 1b). Results of the reactions are summarized in Table I. The obtained polymers and model compounds were soluble in water and polar organic solvents such as methanol, dimethyl sulfoxide, and $\mathrm{N}$-methyl-2-pyrrolidinone. Their structures were determined by ${ }^{1} \mathrm{H}$ and ${ }^{13} \mathrm{C}$ NMR spectroscopy.

Figure 1 depicts ${ }^{1} \mathrm{H}$ NMR spectra of polymer-1 and model-1 in DMSO- $d_{6}$. As seen in Figure 1, peaks due to hydrogen atoms $\mathrm{H}^{\mathrm{a}}, \mathrm{H}^{\mathrm{b}}$, and $\mathrm{H}^{\mathrm{c}}$ of polymer-1 and model-1 appear at approximately $\delta 7.8,7.4$, and 5.9 in a 2:1:2 integral ratio, respectively. The observation of these three signals indicates that the $\pi$-electrons are delocalized along the aminopenta-2,4-dienylidene group. ${ }^{13} \mathrm{C}$ NMR data also supported this view, showing three signals due to the aminopenta2,4-dienylidene group at approximately $\delta 163,162$, and 104 . On the other hand, the ${ }^{1} \mathrm{H}$ NMR peaks assignable to $\mathrm{H}^{\mathrm{a}}$ and $\mathrm{H}^{\mathrm{b}}$ of the aminopenta-2,4-dienylidene group of polymer-2 and model-2 were duplicated with a 3:2 integral ratio between $\mathrm{H}^{\mathrm{a}}+\mathrm{H}^{\mathrm{b}}$ and $\mathrm{H}^{\mathrm{c}}$. The ${ }^{13} \mathrm{C}$ NMR spectra of polymer-2 and model-

${ }^{\dagger}$ To whom correspondence should be addressed (Tel: +81-852-32-6421, Fax: +81-852-32-6421, E-mail: iyamaguchi@riko.shimane-u.ac.jp). 


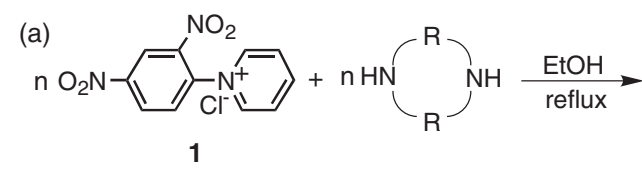

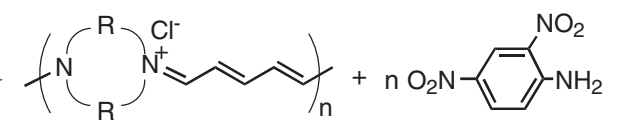

polymer-1: $\mathrm{R}=\left(\mathrm{CH}_{2}\right)_{2} \mathrm{O}\left(\mathrm{CH}_{2}\right)_{2} \mathrm{O}\left(\mathrm{CH}_{2}\right)_{2}$

polymer-2: $\mathrm{R}=\left(\mathrm{CH}_{2}\right)_{2}$

(b)

1
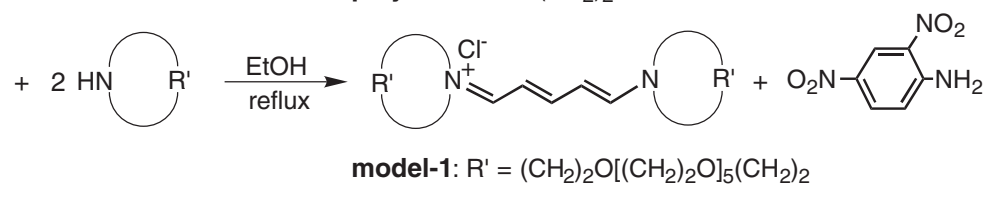

model-2: $\mathrm{R}^{\prime}=\left(\mathrm{CH}_{2}\right)_{5}$

Scheme 1. Synthesis of the polymers and the model compounds.

Table I. Synthesis results and optical and electrochemical properties

\begin{tabular}{lcccccc}
\hline & $\begin{array}{c}\text { Yield } \\
(\%)\end{array}$ & $M_{\mathrm{n}}{ }^{\mathrm{a}}$ & $M_{\mathrm{w}}{ }^{\mathrm{a}}$ & $\begin{array}{c}\eta_{\mathrm{sp}} / c^{\mathrm{c}}, \\
\mathrm{dLg}^{-1}\end{array}$ & $\begin{array}{c}\lambda_{\max }{ }^{\mathrm{d}} \\
/ \mathrm{nm}\end{array}$ & $\begin{array}{c}E_{\mathrm{pa}}{ }^{\mathrm{e}} \\
/ \mathrm{V}\end{array}$ \\
\hline polymer-1 & 43 & 1760 & 6320 & 0.20 & 429 & 0.79 \\
polymer-2 & 93 & $-^{\mathrm{b}}$ & $-{ }^{\mathrm{b}}$ & 0.25 & 471 & 0.70 \\
model-1 & 99 & - & - & - & 420 & 0.78 \\
model-2 & 37 & - & - & - & 422 & 0.93 \\
\hline
\end{tabular}

${ }^{\mathrm{a}}$ Measured by GPC. Eluent $=\mathrm{CHCl}_{3}$. ${ }^{\mathrm{b}}$ Not measured due to poor solubility in the eluent. ${ }^{c} \eta_{\mathrm{sp}} / c$ : Reduced viscosity. Measured at the concentration of $0.06 \mathrm{gdL}^{-1}$ in DMSO at $30^{\circ} \mathrm{C}$. ${ }^{\mathrm{d}} \lambda_{\max }$ : Absorption maximum in DMSO. ${ }^{\mathrm{e}} E_{\mathrm{pa}}$ : Oxidation potential vs. $\mathrm{Ag}^{+} / \mathrm{Ag}$. Measured in an acetonitrile solution of $\left[\mathrm{Et}_{4} \mathrm{~N}\right] \mathrm{BF}_{4}(0.1 \mathrm{M})$. Sweep rate was $50 \mathrm{mVs}^{-1}$.

2 showed three signals due to the aminopenta-2,4-dienylidene group. These NMR data suggest that the $\pi$ electrons in polymer-2 and model-2 are also delocalized along the aminopenta-2,4-dienylidene group.

IR spectra of the polymers and the model compounds showed absorptions due to $v(\mathrm{C}=\mathrm{C})$ and $v(\mathrm{C}=\mathrm{N})$ of the aminopenta-2,4-dienylidene group at approximately $1550 \mathrm{~cm}^{-1}$ and $1440 \mathrm{~cm}^{-1}$, respectively.

As shown in Figure 1, peaks ascribed to the terminal groups of the polymer-1 are not observed in the ${ }^{1} \mathrm{H}$ NMR spectrum. However, the molecular weights of the polymer determined by the GPC measurement were not high $\left(M_{\mathrm{n}}=1760\right.$ and $\left.M_{\mathrm{w}}=6320\right)$. The somewhat low molecular weights of polymer-1 were presumably due to a strong interaction of the polymer with polystyrene gel in the GPC column. The molecular weight of polymer-2 was not able to be determined by GPC due to poor solubility in the eluent. However, the reduced viscosity $\left(\eta_{\mathrm{sp}} / c\right)$ value of polymer-2 was $0.25 \mathrm{dLg}^{-1}$ at the concentration of $0.06 \mathrm{gdL}^{-1}$ in DMSO at $30^{\circ} \mathrm{C}$, whose value was comparable to that of polymer-1 $\left(\eta_{\mathrm{sp}} / c=0.20 \mathrm{dLg}^{-1}\right.$ in a $0.06 \mathrm{gdL}^{-1}$ DMSO solution at $30^{\circ} \mathrm{C}$ ).

Formation of an adduct between polymer-1 and the metal ion was investigated by monitoring of electric conductivity of aqueous solutions of the polymer when the metal ion in limited amounts were added

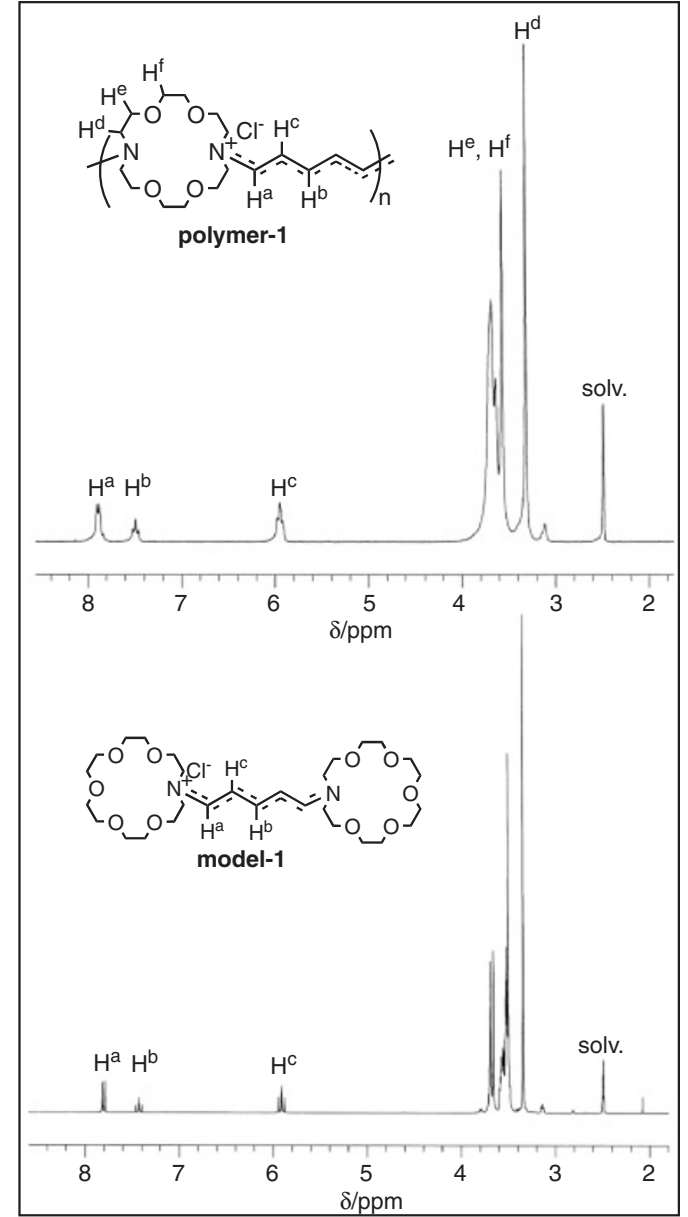

Figure 1. ${ }^{1} \mathrm{H}$ NMR spectra of polymer-1 and model-1 in DMSO- $d_{6}$.

to the polymer solutions. $\mathrm{Ag}^{+}$and $\mathrm{K}^{+}$were selected as the metal ions since the two ions had a suitable size to be included into DA18C6. ${ }^{8,9}$ Figure 2 depicts electric conductivity $(\sigma)$ changes of the aqueous solution of polymer-1 by adding $\mathrm{AgClO}_{4}$ or $\mathrm{KClO}_{4}$ to the solutions. When the metal perchlorates were added to the polymer solutions, no precipitate was formed form the solutions. As shown in Figure 2a, the conductivities of the polymer solutions are slightly decreased by adding $\mathrm{AgClO}_{4}$ to the equivalence point and increase in proportion to the amounts of $\mathrm{AgClO}_{4}$ after the 


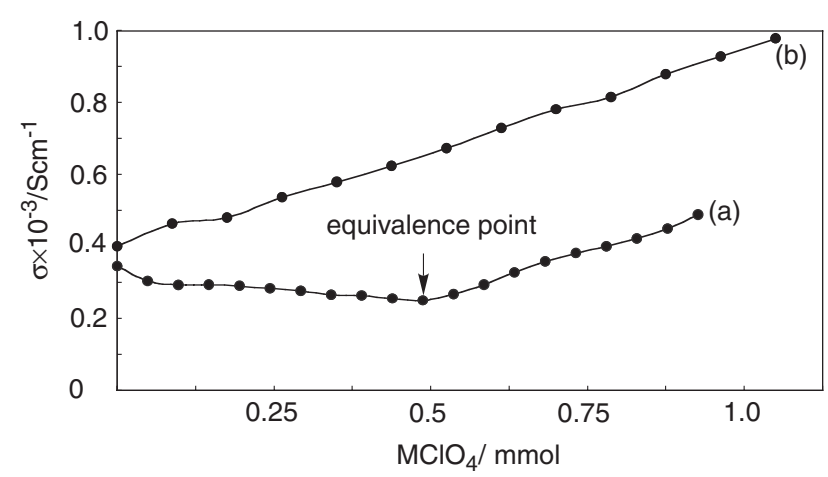

Figure 2. Conductivity changes of an aqueous solution of polymer-1 $(0.5 \mathrm{mmol} / \mathrm{L})$ by addition of $\mathrm{MClO}_{4}(\mathrm{M}=\mathrm{Ag}$; (a), $\mathrm{K}$; (b)).

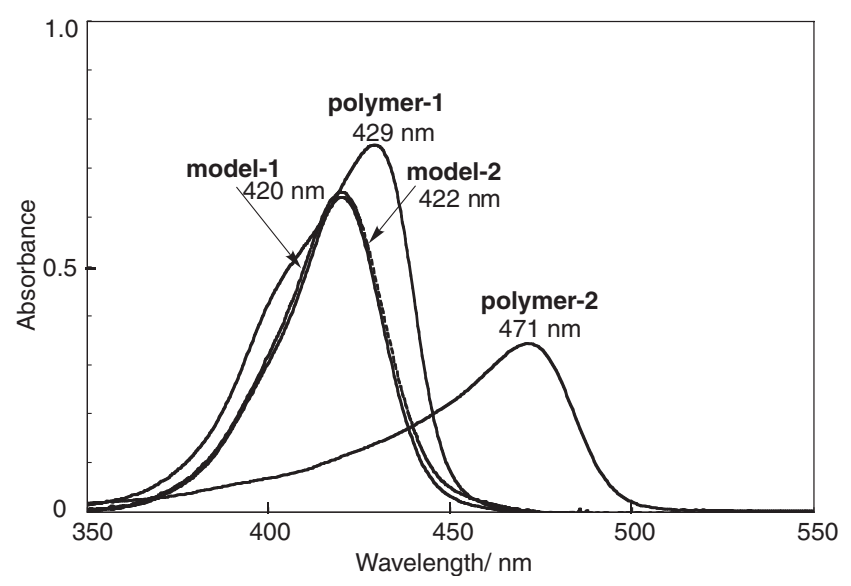

Figure 3. UV-vis spectra of polymer-1, polymer-2, model-1, and model-2 in DMSO.

equivalence point. Whereas the conductivities of the polymer-2 solutions increased in proportion to the amounts of $\mathrm{AgClO}_{4}$ added. These data suggest that $\mathrm{Ag}^{+}$was included into DA18C6 in the polymer chain until the equivalence point. Whereas the electric conductivities of the polymer-1 solution increase in proportion to the amounts of $\mathrm{KClO}_{4}$ added, suggesting that $\mathrm{K}^{+}$is not included into DA18C6 in the polymer chain, as depicted in Figure 2b. It is known that diazacrown ethers bearing neutral nitrogen atom classified as soft atoms tend to include transition metal ions classified as a soft ion rather than alkaline metal ions classified as a hard ion. ${ }^{8,9}$ Although the nitrogen atoms of DA18C6 of polymer-1 have a positive charge, the difference of inclusion behavior between $\mathrm{Ag}^{+}$and $\mathrm{K}^{+}$ seems to be scribed to a soft basic property of the nitrogen atoms.

Figure 3 depicts UV-vis spectra of polymer-1, polymer-2, model-1, and model-2 in DMSO. The absorption data are summarized in Table I. Model-1 and model-2 show absorption maxima $\left(\lambda_{\max }\right)$ at essentially the same position. The $\lambda_{\max }$ of polymer-1 appears at a wavelength slightly longer than that of model-1.

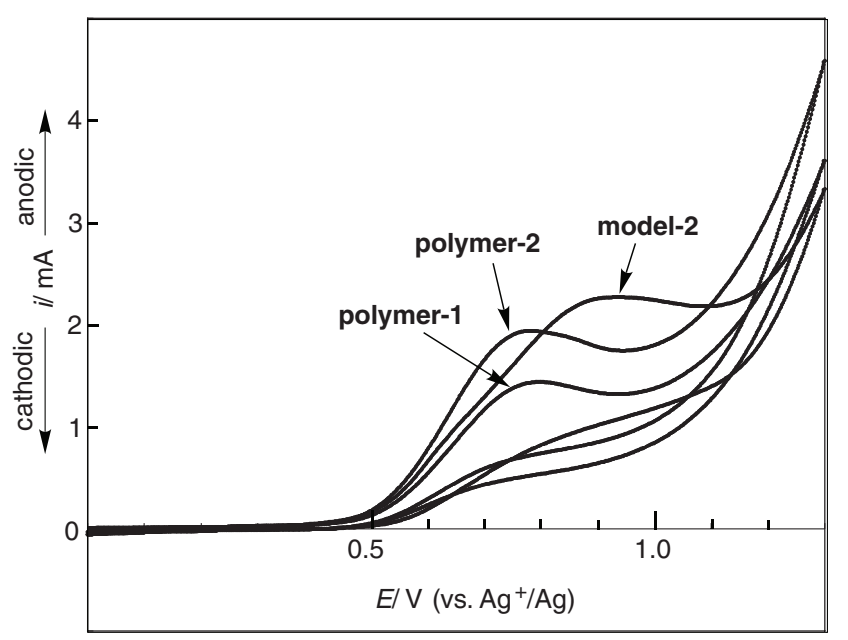

Figure 4. Cyclic voltammograms of polymer-1, polymer-2, and model-2 in a DMSO solution of $\left[\mathrm{Et}_{4} \mathrm{~N}\right] \mathrm{BF}_{4}(0.1 \mathrm{M})$. The scan rate was $50 \mathrm{mVs}^{-1}$.

Whereas polymer-2 shows $\lambda_{\max }$ at a wavelength considerably longer as compared to model-2 and polymer-1, probably due to transfer of a positive charge on the iminium group between the aminopenta-2,4-dienylidene groups beyond the piperadinium ring. It has been reported that nonconjugated polymers such as cis-poly-1,4-isoprene cause bathochromic shift of an absorption peak by p-doping with iodine that leads generation of a positive charge on the double-bond site. ${ }^{10-12}$ For polymer-1, such a charge transfer between the aminopenta-2,4-dienylidene groups can not take place since the aminopenta-2,4-dienylidene groups are separated by the larger DA18C6 ring. The UV-vis spectrum of polymer-1 in DMSO solution was essentially the same to that in the presence of $\mathrm{Ag}^{+}$, indicating that the inclusion of $\mathrm{Ag}^{+}$into DA18C6 brought about no effect on the $\pi$-conjugation system of the aminopenta-2,4-dienylidene group.

The polymers and model compounds were electrochemically active in a DMSO solution of $\left[\mathrm{Et}_{4} \mathrm{~N}\right] \mathrm{BF}_{4}$ $(0.1 \mathrm{M})$. Cyclic voltammetry $(\mathrm{CV})$ measurements suggested that the polymers underwent an electrochemical oxidation in the DMSO solution including $\left[\mathrm{Et}_{4} \mathrm{~N}\right] \mathrm{BF}_{4}$. The CV data are summarized in Table I. The cyclic voltamogram of polymer-1 was resemble to that of model-1. Whereas the oxidation potential of polymer-2 is lower than that of model-2, which corresponds to the observation of $\lambda_{\max }$ of polymer-2 at a longer wavelength as compared to model-2. As shown in Figure 4, the corresponding reduction peak does not appear in the cyclic voltammograms, probably due to formation of a stable adduct between iminium cations of the polymers and model compounds and $\mathrm{BF}_{4}{ }^{-}$to prevent electrochemical reduction (p-undoping).

In conclusion, the reactions of 1 with DA18C6 and piperadine gave polymer-1 and polymer-2 that were 
consisted of the 5-alkane-penta-2,4-dienylideneammonium chloride unit. The corresponding model compounds were also obtained. The ${ }^{1} \mathrm{H}$ NMR spectra suggested that the $\pi$-electrons of the penta-2,4-dienylideneammonium group of the polymers and model compounds were delocalized. The electric conductivity measurements indicated that the DA18C6 of polymer-1 was able to include $\mathrm{Ag}^{+}$in solution. The polymers and the model compounds are electrochemically active in solutions, as revealed by cyclic voltammetry.

Electronic Supporting Information Available. General, Synthesis and Reference. These materials are available via. the Internet at http://www.spsj.or.jp/c5/ pj/pj.htm.

\section{REFERENCES}

1. U. Tunca and Y. Yabci, Prog. Polym. Sci., 19, 233 (1994).

2. B. Fabre and J. Simonet, Coord. Chem. Rev., 178-180, 1211 (1998).
3. J. M. G. Cowie, Polym. Int., 47, 20 (1998).

4. D. Spiro, S. D. Alexandratosa, and C. L. Stine, React. Funct. Polym., 60, 3 (2004).

5. W. M. Feigenbaum and R. H. Michel, J. Polym. Sci., A-1, 9, 817 (1971).

6. S. H. Chan, W. T. Wong, and W. K. Chan, Chem. Mater., 13, 4635 (2001).

7. I. Yamaguchi, Y. Gobara, and M. Sato, J. Polym. Sci., Part A: Polym. Chem., 45, 1507 (2007).

8. R. M. Izatt, L. D. Hansen, D. J. Eatough, J. S. Bradshaw, and J. J. Christensen, "Metal-Ligand Interactions in Organic Chemistry and Biochemistry, Part 1", Reidel, Dordrecht, 1977, p337.

9. F. Vögtle and E. Weber, "The Chemistry of the Ether Linkage, Suppl. E, Part 1", Wiley, Chichester, 1981, p59.

10. M. Thakur, Macromolecules, 21, 661 (1988).

11. M. Thakur and B. S. Elman, J. Chem. Phys., 90, 2042 (1989).

12. M. Thakur, R. Swamy, and J. Titus, Macromolecules, 37, 2677 (2004). 